\title{
A leitura de textos de divulgação científica na constituição de professores de química
}

\author{
Reading texts to the scientific publicizing in the \\ constitution of the chemistry teachers
}

Judite Scherer Wenzel ${ }^{1}$

\begin{abstract}
Resumo
O presente ensaio consiste num diálogo sobre a inserção da leitura de Textos de Divulgação Científica na formação inicial de professores de Química. A prática da leitura ocorre num grupo de estudos com encontros mensais que são sistematicamente acompanhados. A argumentação aponta a apropriação da linguagem química como condição inicial para a formação do pensamento químico. E, num diálogo com Vigotski (2000), Leontiev (1978) e Bakthin (2006) compreende-se a linguagem como constitutiva do sujeito, apresenta-se a importância do uso de diferentes estratégias para a leitura e reforça-se o posicionamento do leitor frente ao texto. Os resultados apresentam os modos de organização das práticas de leitura vivenciadas no grupo e, alguns aspectos apontados pelos participantes, que possibilitam visualizar a prática da leitura de Textos de Divulgação Científica como um espaço que qualifica tanto o uso da linguagem química como a constituição de professores leitores. Por fim, ressalta-se a importância da propagação da leitura como recurso potencial, a ser utilizado em sala de aula, contribuindo na formação de sujeitos capazes de se posicionar de forma mais qualificada frente às informações e acontecimentos.
\end{abstract}

\footnotetext{
${ }^{1}$ Possui graduação em Quimica Licenciatura Plena pela Universidade Federal de Santa Maria (2004), mestrado e doutorado em Educação nas Ciências pela Universidade Regional do Noroeste do Estado do Rio Grande do Sul $(2007 ; 2013)$. É professora adjunto I da Universidade Federal da Fronteira Sul. Professora permanente do Programa de Pós Graduação em Ensino de Ciências (PPGEC). Atuou como coordenadora do Curso de Química Licenciatura de 2013 à 2017. Em 2016 coordenou o PIBID Interdisciplinar e atualmente atua como coordenadora do PIBID Química. Coordena o Grupo de Leitura Interativa de Textos de Divulgação Científica. Atua como vice coordenadora do Programa de Extensão Ciclos Formativos em Ensino de Ciências e Matemática e como professora colaboradora no PET Ciências. Tem experiência na área do Ensino, com ênfase em Ensino de Ciências e Química nos seguintes temas: Educar pela Pesquisa, Formação de Professores, Significação Conceitual, Linguagem Química. Integrante do Grupo de Estudos e Pesquisas em Ensino de Ciências e Matemáticas (GEPECIEM) da UFFS.
} 
Palavras Chave: Formação Inicial. Linguagem Química. Leitura Interativa.

\begin{abstract}
The present paper consists in a discourse about the reading insertion of Scientific Publicizing texts in the initial formation of Chemistry teachers. The reading practice occur in a study group with monthly meetings which are systematically accompanied. The argumentation point to the Chemical language appropriation as an initial condition to the formation of the Chemical thinking. And, in a discourse with Vigotski (2000), Leontiev (1978) and Bakthin (2006) is understandable the languague as constitutive of the person, it introduce the importance of different strategies to reading and reinforce the reader position at the head of the text. The results show the ways of the reading practice organization experienced in the group, and some aspects noted by the participants, which enable to view the reading practice of Scientific Publicizing texts as a space that qualify as the Chemical Language use as the reader teachers formation. Finally, it reinforce the importance of the reading propagation as potential resource, to be used in the classroom, contributing in the person's formation able to position itself in a more qualified way before information and facts.
\end{abstract}

Key words: Initial Formation. Chemical Language. Interactive Reading.

\title{
Introdução
}

O ensaio aqui apresentado versa sobre uma pesquisa que está sendo desenvolvida junto a um grupo ${ }^{2}$ de Estudos de Leitura de Textos de Divulgação Científica (TDC) no âmbito de um Curso de Licenciatura em Química de uma Universidade Federal do Interior do Rio Grande do Sul. A problemática da investigação decorre da necessidade de repensar os modos de execução e as escolhas dos tipos de leituras junto ao ensino de química, em especial, na formação inicial de professores. Na maioria das vezes, conforme aponta Flôr (2015), as leituras desenvolvidas nas aulas de química, nos diferentes niveis de ensino, priorizam habilidades técnicas, contemplando aspectos

$2 \mathrm{O}$ grupo iniciou suas atividades em setembro do ano de 2016 tendo como objetivo principal propor e acompanhar práticas de leitura interativa de TDC em contexto de formação inicial de professores. 
A leitura de textos de divulgação científica...

quantitativos e classificatórios. Tais práticas reproduzem uma visão de Ciência como verdade única e inquestionável. O texto é visto apenas como fonte de informação e o ato de ler se resume na simples repetição de palavras sem qualificar os significados atribuídos à elas pelos estudantes.

A significação, nas palavras de Leontiev (1978, p. 95), é compreendida como "a entrada na minha consciência, o reflexo generalizado da realidade elaborado pela humanidade e fixado sob forma de conceitos, de um saber ou mesmo de um saber fazer". E, nos dizeres de Vigotski (2000, p. 368), "ser significado é o mesmo que estar em determinadas relações de generalidade com outros significados [...] a natureza do conceito se revela de forma mais completa nas relações específicas de um dado conceito com outros conceitos". Assim, para ser capaz de atribuir algum significado às palavras é preciso tornar para si o que foi historicamente construído. Diz-nos Vigotski (2000, p. 465) que "tomada isoladamente no léxico, a palavra tem apenas um significado. Mas este não é mais que uma potência que se realiza no discurso vivo, no qual o significado é apenas uma pedra no edificio do sentido".

Em especial, no caso da linguagem Química, atribuir significado é conseguir fazer uso consciente das palavras específicas de tal Ciência em diferentes contextos, atribuindo a elas os significados historicamente estabelecidos. O simples fato de repetir uma palavra precede a tomada de consciência, é, apenas, o início da construção do seu significado. Vigotski (2000) em seu trabalho de desvendar os processos humanos complexos reporta-se a tal fato com o estudo do comportamento da criança que, de acordo com as observações realizadas, faz uso das palavras sem ter a consciência do seu significado. O autor (2000) exemplifica isso com o uso das palavras porque, como, ou, quando por crianças, antes mesmo de elas entenderem as relações causais, condicionais ou temporais de tais palavras, isto é, antes de elas fazerem uso consciente de tais palavras, elas podem, por exemplo, até expressar de maneira correta o uso da palavra porque, indicando a causa, mas tal uso não significa que a criança saiba, em outras situações que exigem a tomada de consciência, identificar que a palavra porque remete para a causa. A criança simplesmente reproduz o discurso no qual está inserida. Esse fazer uso da palavra, esse reproduzir, é o passo inicial para a 
significação conceitual, para iniciar a formação do pensamento abstrato. Fazer uso ou apropriar-se das palavras é apenas o inicio do processo de significação, antecede a formação do pensamento conceitual.

Nessa direção, compreendemos com Vigotski (2000), que, o sujeito ao usar uma nova palavra, o processo de significação está apenas iniciando, mas é no uso da palavra em diferentes contextos, em processos mediados, que se vai amadurecendo e ampliando os níveis de generalização. Ainda, numa outra interpretação, Bakhtin (2010) caracteriza a existência da palavra para qualquer falante em três aspectos: palavra da língua neutra que não pertence a ninguém; como palavra dos outros, que carrega enunciados alheios, e, por último, como palavra própria. Segundo esse autor (2010, p. 294), "quando passo a fazer uso da palavra ela vai se tornando minha, pois está compenetrada da minha expressão", e nesse processo, no entendimento de Bakhtin, a minha palavra traz junto a dos outros, com diferentes graus de interpretação e de sentidos, e ela vai se tornando cada vez mais minha na medida em que faço uso consciente da mesma em diferentes situações.

Dessa forma, um estudante que consegue relacionar corretamente as palavras/símbolos/equações específicas da química para explicar um determinado fenômeno apresenta indícios da formação do pensamento químico, pois, nessa situação, o seu uso não foi apenas de forma mecânica ou inconsciente, mas desencadeou a capacidade de realizar diferentes relações conceituais, o que, por sua vez, remete para a significação e para a formação do pensamento conceitual. Nessa direção, apontamos como primordial a inserção de espaços formativos que possibilitem aos sujeitos a capacidade de realizar relações conceituais de maneira consciente e, compreendemos que a prática da leitura pode vir a contribuir para isso, desde que envolva o leitor, que não seja uma simples repetição mecânica, mas que o instigue diálogos seja do leitor com o texto, do leitor com outros leitores, num movimento de leitura interativa. Geraldi (2010) também aponta que o uso consciente da linguagem consiste em tornar seu, pela interação com o outro, o que é social, dai a importância da inserção de espaços formativos que possibilitem o uso dialogado da linguagem química. 
A leitura de textos de divulgação científica...

Nessa direção, ressaltamos a importância das interações discursivas estabelecidas no processo de significação. Nas palavras de Cunha e Giordan (2015, p. 80) “compreender a enunciação de outrem significa encontrar o seu lugar no elo da cadeia da enunciação e, para compreender, é preciso que se estabeleçam relações de negociação entre os interlocutores". Assim, acreditamos que uma prática de leitura que instigue ao sujeito dialogar tanto com o texto como com outros leitores, possibilitará avanços no seu estágio de desenvolvimento, enriquecendo, com isso, as suas atividades cognitivas. Tal fato mostra-se mais importante num contexto de formação inicial de professores devido às especificidades formativas, uma vez que, para se tornar um bom professor de química, não é suficiente saber palavras isoladas de química, mas é necessário ter um pensamento integrado de conhecimentos na forma da química sobre o mundo, para assim ser capaz de dialogar em diferentes contextos com o uso dos conceitos químicos realizando as necessárias relações e mediações, a fim de possibilitar práticas de ensino que sejam significativas aos estudantes.

Importante destacar que a prática de leitura que está sendo apresentada tem como finalidade qualificar o posicionamento dos participantes do grupo frente ao texto, de possibilitar espaços para que ocorram diálogos, instigando aos participantes a exporem a sua opinião, para assim, oportunizar que linguagem e pensamento se constituam mutuamente (VIGOTSKI, 2000) num processo interativo. E, tendo em vista que as práticas de leitura que predominam nas aulas de química consistem na leitura do livro didático, de relatórios técnicos ou, de artigos científicos, optou-se por fazer uso da leitura de TDC.

As autoras Ferreira e Queiroz (2015, p. 131) ao dialogar sobre o uso de TDC nas aulas de química destacam que esses textos "têm recebido destaque, com seus beneficios sendo apontados na literatura especializada, os quais passam pelo simples estímulo ao hábito da leitura, podendo alcançar o desenvolvimento da capacidade crítica e uma compreensão mais adequada sobre a ciência por parte do alunado". Mas, apontam a baixa frequência em que os TDCs têm sido abordados nos Cursos de formação de professores, e afirmam ser necessário "mais estudos nesse cenário e de preparação e 
incentivo aos docentes para a sua utilização", o que reforça a prática de leitura que estamos apresentando.

A fim de potencializar as interações do leitor com o texto e com os demais participantes do grupo, são realizadas diferentes estratégias tanto para a realização das leituras como para os diálogos nos encontros do grupo. Na sequencia passamos a dialogar sobre alguns aspectos teóricos quanto à compreensão da prática da leitura, abordamos as especificidades do discurso apresentado no TDC e, retratamos as compreensões acerca do processo de interação discursiva, de apropriação e de significação da linguagem por meio da prática leitura.

\section{A prática da Leitura, Textos de Divulgação Científica e Interações Discursivas}

Especificamente sobre a escolha da prática da leitura o entendimento, está ancorado em Marques (2001) que a defende como uma prática em que o leitor deve se posicionar frente ao texto, dar a sua resposta, num movimento responsivo. Aliado a isso, está uma vivência formativa que retratou o uso da escrita e reescrita na formação inicial de professores (AUTORA, 2014) e que apontou para a necessidade da superação de leitores e de escritores passivos e estáticos, passando para sujeitos participantes. Nessa, o foco esteve direcionado para a escrita orientada e foi possivel, mediante o caráter responsivo existente nessa prática, evidenciar que o licenciando ao ser instigado a escrever sobre determinado fenômeno de maneira contextualizada e dialógica teve indícios de construção do seu pensamento químico.

Esse posicionamento responsivo é entendido com Bakhtin (2006, p. 135) pela compreensão estabelecida no diálogo, que consiste em "opor à palavra do locutor uma contrapalavra". Assim, com base em Bakhtin (2006) um discurso para ser considerado dialógico deve estar orientado para o outro que pode, ou não estar fisicamente presente, ou seja, ao ler ocorre um diálogo com o autor do texto, e assim, é também uma forma de diálogo. Nessa direção Solé (1998, p. 22) aponta que a prática de leitura é um processo de interação entre o leitor e o texto e, a significação atribuída ao texto implica numa "construção que 
A leitura de textos de divulgação científica...

envolve o texto, os conhecimentos prévios do leitor que o aborda e os seus objetivos".

Mas essa prática de leitura dialogada ainda precisa ser apreendida pela maioria dos sujeitos, no caso em questão, pelos licenciandos. Barbosa e Hess (2010) destacam que é no processo de leitura e de releitura que o aluno se faz como alguém que pensa e que significa o que faz. Considerando os espaços de leitura na formação inicial em Química, os autores Júnior e Silva (2007, p. 1367) retratam que predomina a carência ou o uso não orientado de leituras. As quais, em sua maioria, se reduzem à leitura do livro didático de Química, e tal prática pouco contribui para a constituição de leitores "com responsabilidade social e politica e com capacidade de julgar, avaliar e decidir no campo do domínio técnico científico". Nessa direção, os autores (2007) defendem a importância da inserção de espaços para que o estudante aprenda a ler, não a leitura apenas informativa, mas, que pela leitura ele consiga estabelecer um diálogo com o texto e apresentar um posicionamento.

Larossa (2015, p.142) ao escrever sobre a prática da leitura como uma lição em sala de aula ressalta que "depois da leitura, o importante não é o que nós saibamos do texto o que nós pensamos do texto, mas o que - com o texto, ou contra o texto ou a partir do texto - nós sejamos capazes de pensar". Considerando essas posições frente à prática de leitura o grupo visa oportunizar uma prática de leitura que possibilite a construção do pensamento químico sobre o mundo, o que requer a significação da linguagem química. A formação do pensamento químico, entre outras particularidades, requer do sujeito à capacidade de compreender os aspectos históricos que são constitutivos na elaboração dos conhecimentos químicos, as especificidades da linguagem química (leis, conceitos, fórmulas, imagens, representações...) e saber relacionar tais aspectos ao seu contexto social, tendo em vista outra compreensão sobre o mundo. No entendimento de Vigotski (2000), como já foi referido, o pensamento somente é possivel com a palavra, daí a escolha pelo uso da leitura em contexto de formação inicial de professores e, ainda, tendo em vista as necessárias relações a serem estabelecidas no processo de significação optou-se pela escolha do gênero discursivo TDC. 
Com Bakthin (2010) compreendemos que o gênero discursivo se caracteriza como um enunciado que apresentam conteúdos temáticos, estilo próprio e, também, uma construção composicional específica. Nas palavras do autor (2010, p. 293), “o gênero do discurso não é uma forma da lingua, mas uma forma típica do enunciado; como tal forma, o gênero inclui certa expressão típica a ele inerente”. Cunha e Giordan (2015, p. 68) reforçam isso ao apresentarem o TDC como uma "nova estruturação do discurso, de um novo gênero no qual a base de informação provém do discurso científico".

Em particular o TDC apresenta a linguagem científica de uma forma mais contextualizada, histórica e, ainda, algumas vezes, de modo divertido. Tais características estão relacionadas com a sua finalidade que consiste em divulgar a ciência e o seu direcionamento para o outro, isso corrobora a fala de Bakhtin (2010, p. 301) de que "o papel dos outros para quem se constrói o enunciado é excepcionalmente grande". No entendimento de Gouvêa (2015, p. 19) a divulgação da ciência envolve uma "reelaboração do discurso científico e de alguma forma algum processo de enculturação". E o mesmo autor (2015, 36) ressalta que "é fundamental que se insira na formação inicial o uso de materiais de divulgação da ciência e da técnica, no sentido de ampliar a formação desse futuro professor na perspectiva da sua cidadania".

Os recursos lexicais do TDC, no entendimento de Cunha e Giordan (2015), se caracterizam pelo uso de analogias, exemplificações, comparações e metáforas, sendo que tal modo de linguagem os diferencia de um discurso apenas científico. Ferreira e Queiroz (2012), com base em Zamboni, caracterizam os TDC contemplando três características: cientificidade, didaticidade e laicidade. A laicidade, segundo as autoras, consiste nos indícios do discurso cotidiano devido à presença de diferentes formas de contextualização. A didaticidade está relacionada a aspectos do discurso didático como explicações, retomadas e orientações metodológicas.

Mas, importante ressaltar que, apesar do direcionamento, dos recursos lexicais utilizados serem mais amplos do que no discurso científico e da sua maior proximidade com aspectos do cotidiano, ainda assim, para a compreensão do TDC é preciso um entendimento de diferentes termos específicos, que remetem ao entendimento de outros termos, num movimento 
A leitura de textos de divulgação científica...

que requer o estabelecimento de sucessivas relações conceituais. Tal visão está ancorada em Vigotski (2000, p. 398) que diz que o "significado da palavra só é um fenômeno de pensamento na medida em que o pensamento está relacionado à palavra e nela materializado, e vice versa" e que não é possivel realizar qualquer pensamento sem palavras. Esses entendimentos superam a visão da linguagem apenas como instrumento de comunicação, mas apresentam-na como constitutiva dos sujeitos. Acreditamos que ao fazer uso da palavra num processo de leitura interativa o licenciando amplia os sentidos estabelecidos para as palavras, num processo de evolução do significado dos conceitos químicos e assim, o seu pensamento conceitual químico vai sendo constituído e qualificado.

Também nesse movimento interativo, de abertura ao diálogo, é possivel que o estudante passe a compreender os conhecimentos Químicos como uma construção humana, superando a ideia do pronto e inacabado. Considerando a importância das interações estabelecidas no processo de leitura, destacamos as palavras de Flôr (2015, p. 57) ao acompanhar o perfil de leitores em aulas de química no Ensino Médio ao mencionar que para a formação de sujeitos leitores "não basta mudar as fontes de leitura, pois o problema não é tanto o que o sujeito lê, mas a forma pela qual essa leitura lhe é possibilitada". Larossa (2015, p.139), nessa mesma direção chama atenção para a necessidade de uma entrega mútua, um duplo devir: "hospitalidade do livro e disponibilidade dos leitores". Também nessa direção Solé (1998, p. 23) destaca que no processo de interação/ compreensão do texto "intervêm tanto o texto, sua forma e conteúdo, como o leitor, suas expectativas e conhecimentos prévios".

Assim, ressaltamos que, para além do posicionamento frente ao texto, o gosto pela leitura deve ser "aguçado" e, para tanto, apontamos que o uso de diferentes estratégias de leitura aliada a linguagem dos textos podem vir a contribuir para isso. No caso da formação inicial de professores de química, importante ampliar os modos de leituras para além da leitura obrigatória, que muitas vezes, consiste num ciclo fechado de interpretação de texto, com base em perguntas e respostas. O que estamos propondo é uma prática de leitura mais dialogada e, para tanto, tendo como objetivo ampliar a participação dos licenciandos eles são convidados a se tornarem protagonistas na condução do 
diálogo do texto. $\mathrm{Na}$ sequencia apresentamos aspectos de organização do grupo de leitura e, por fim, os resultados pinçados das vivências com o grupo.

\section{Modos de Organização do Grupo de Leitura}

O grupo de Estudos de Leitura Interativa de textos de Divulgação Científica teve início em setembro do ano de 2016. Atualmente conta com 16 licenciandos do Curso e 4 professoras formadoras (três da área de ensino de Química e uma da área da Química), a participação é voluntária e o convite foi estendido à todos os licenciandos. De um modo geral, os licenciandos que participam do grupo apresentam diferentes vivências formativas, alguns já cursaram Estágios Curriculares Supervisionados, outros ainda numa etapa mais inicial do Curso. Alguns são bolsistas de Iniciação à Docência (PIBID), de Educação Tutorial (PET), de Iniciação Científica (IC) e outros apenas estudantes. Tal multiplicidade enriquece os diálogos no grupo, uma vez que compreendemos com Vigotski (2000) que o processo de ensino é qualificado nas relações assimétricas.

Os encontros são mensais e consistem no diálogo referente às impressões da leitura do TDC. Para fins de acompanhamento todos os encontros são gravados e, algumas vezes, os participantes são convidados a responder algum questionário, ou realizar alguma avaliação sobre o andamento do processo. Todos os participantes assinaram o Termo de Consentimento Livre e Esclarecido (TCLE) tendo em vista os preceitos éticos da pesquisa.

Em especial, os encontros de leituras são planejados pelos participantes que se organizam em grupos, sendo que cada grupo é responsável por uma estratégia de diálogo a ser estabelecida nos encontros. O grupo conta com voluntários que encaminham os convites e organizam os participantes dos grupos. Na sequencia apresentamos alguns aspectos mais direcionados ao grupo e que se caracterizam como uma descrição da vivência e, retratamos alguns posicionamentos dos participantes que foram escritos numa das avaliações realizadas. De um modo geral, a argumentação que segue, reforça a importância da prática da leitura tanto para a significação da linguagem química como para a constituição de professores leitores. 
A leitura de textos de divulgação científica...

\section{A vivência no Grupo de Leitura: Indícios da constituição do professor Leitor e da Significação da Linguagem Química}

A criação do grupo de leitura considerou, em especial, o contexto de formação inicial de professores e, a necessária relação do licenciando com a linguagem química, uma vez que "a significação conceitual é possível somente mediante o uso dos conceitos científicos em espaços distintos” (AUTORA e OUTRO, 2016). Possibilitar ao licenciando visualizar a linguagem química com outros aspectos, num movimento mais contextualizado, como é o caso da linguagem apresentada no TDC, foi considerado como um caminho para ampliar a visão simplista da química como sendo um conhecimento isolado, com uso de fórmulas, de símbolos representados em livros didáticos ou, em artigos científicos sem nenhuma relação com o dia a dia, com aspectos históricos e/ou curiosos.

Para a leitura, até o momento, foram escolhidos dois livros que se caracterizam pela linguagem que apresentam como TDC: Tio Tungstênio: memórias de uma infância química de autoria de Oliver Sacks e, Barbies, Bambolês e Bolas de Bilhar, de autoria de Joe Schwarcz. A escolha por essas obras esteve relacionada ao fato de serem livros conhecidos por uma das professoras formadoras, que já vinha fazendo uso dos mesmos em suas aulas.

Visando qualificar a participação dos licenciandos e, aprimorar o seu desenvolvimento cognitivo frente à leitura, diferentes estratégias estão sendo realizadas, conforme está retratado no quadro 01:

Quadro 01: Encontros, Capítulos e Estratégias de Leitura

\begin{tabular}{|l|l|ll|}
\hline ENCONTRO & LIVRO E CAPITULO DO TDC & \multicolumn{2}{|c|}{ ESTRATÉGIA DE LEITURA } \\
\hline PRIMEIRO & $\begin{array}{l}\text { Capítulo 10 do livro Tio } \\
\text { Tungstênio: memórias de uma } \\
\text { infância quimica, intitulado } \\
\text { uma linguagem quimica. }\end{array}$ & $\begin{array}{l}\text { Elaboração de } \\
\text { participantes e } \\
\text { mesmas. }\end{array}$ & $\begin{array}{l}\text { Perguntas pelos } \\
\text { socialização das }\end{array}$ \\
\hline SEGUNDO & $\begin{array}{l}\text { Capitulo 16 do livro Tio } \\
\text { Tungstênio: memórias de uma } \\
\text { infância química, intitulado O Olaboração de perguntas pelos } \\
\text { jardim de Mendeleiev. }\end{array}$ & $\begin{array}{l}\text { Elarticipantes. Troca de leitura das } \\
\text { perguntas em pequenos grupos, com } \\
\text { outra elaboração de pergunta para } \\
\text { socialização. }\end{array}$ \\
\hline
\end{tabular}




\begin{tabular}{|c|l|l|}
\hline TERCEIRO & $\begin{array}{l}\text { Capítulo 01 do livro Barbies, } \\
\text { bambolês e bolas de bilhar, } \\
\text { intitulado Essas fascinantes } \\
\text { substâncias químicas. }\end{array}$ & $\begin{array}{l}\text { Seleção de fotografias ou imagens } \\
\text { sobre o subcapitulo com a norteação } \\
\text { do diálogo no encontro. }\end{array}$ \\
\hline QUARTO & $\begin{array}{l}\text { Capitulo 02 do livro Barbies, } \\
\text { Bambolês e Bolas de Bilhar, } \\
\text { intitulado Goela a baixo. }\end{array}$ & $\begin{array}{l}\text { Método de imagens e estruturas } \\
\text { quimicas para ilustrar os capitulos, } \\
\text { também cada participnate foi } \\
\text { desafiado a compartilhar uma frase } \\
\text { que tivesse despertado curiosidade e } \\
\text { que definisse o seu capitulo. }\end{array}$ \\
\hline
\end{tabular}

Fonte: autoria próprria

Nos dois primeiros encontros que estão apresentados no quadro 01 as estratégias de leitura foram encaminhadas por uma das professoras formadoras e por licenciandos voluntários da pesquisa, nos demais, as estratégias foram planejadas e organizadas por todos os participantes. Passamos a dialogar sobre tais estratégias de leitura a fim de compreender os modos de organização para com isso, apresentar a prática de leitura defendida neste ensaio. A escolha pela descrição desses quatro encontros esteve condicionada ao fato da representação das estratégias de leitura com as demais que estão sendo vivenciadas no grupo.

Para o primeiro encontro a estratégia de leitura que foi encaminhada, conforme o quadro 01 , consistiu na solicitação da elaboração de perguntas ${ }^{3}$ por parte dos participantes, referentes ao capítulo 10, do livro Tio Tungstênio: memórias de uma infância química, intitulado Uma Linguagem Química. As perguntas elaboradas foram entregues no dia do encontro e conduziram o diálogo no grande grupo. Para o segundo encontro, o TDC foi o capítulo 16, $O$ jardim de Mendeleiev, também do livro de autoria de Oliver Sacks, e a estratégia também consistiu na elaboração de perguntas pelos participantes para serem entregues no encontro. Mas, no dia do encontro as perguntas foram distribuidas em subgrupos. Cada subgrupo dialogou sobre as perguntas que recebeu e, foi desafiado a elaborar coletivamente, uma nova pergunta. Após essa atividade todos os participantes se reuniram para a socialização. 
A leitura de textos de divulgação científica...

Importante ressaltar que, a mudança de estratégia no segundo encontro, ocorreu, pois, no primeiro, a maioria das intervenções, foi realizada pelas professoras formadoras, sendo que os licenciandos, pouco se autorizaram em participar. Na formação de subgrupos conseguimos qualificar essa participação. Em especial, esses dois encontros tiveram como modo de organização a elaboração de perguntas, além de motivar a leitura, a escolha por essa estratégia esteve ancorada em Moraes (2010, p.140) ao afirmar que "perguntar e responder, ter problemas e encontrar soluções constituem a essência do aprender em que estamos constantemente envolvidos." Ainda, ressaltamos, com Moraes (ibidem) que elaborar uma pergunta consiste na "relação entre o que já conhecemos e algo de que necessitamos ou que gostariamos de conhecer e que ainda não possuímos." ou seja, o questionamento que irá qualificar o processo de aprender necessita de um posicionamento daquele que pretende construir um conhecimento. Assim, tal processo visou instigar os participantes à leitura do texto e, ainda, conduzir o diálogo no grupo.

Outros encontros contemplaram estratégias que foram conduzidas pelos participantes do grupo, como por exemplo, para o capítulo intitulado Essas fascinantes substâncias químicas, do livro Barbies, Bambolês e Bolas de Bilhar, a estratégia de leitura utilizada consistiu em cada participante representar algum aspecto do texto por meio de alguma imagem (fotografia ou desenho). No dia do encontro as imagens foram apresentadas e os participantes foram indicando as relações da imagem com o texto. Essa estratégia foi bastante descontraída e fez com que o grupo participasse na busca de identificar a imagem com a leitura.

Para o capítulo intitulado Goela a Baixo, também do livro Barbies, Bambolês e Bolas de Bilhar, a estratégia de leitura utilizou novamente o recurso de imagens, com figuras e representações de fórmulas químicas, mas o que diferenciou da outra estratégia foi que todas as imagens foram trazidas ao encontro pelo grupo organizador ficando como responsabilidade dos participantes dialogar sobre as imagens e trazer algo que tenha lhe chamado mais atenção do texto. Aliado a isso, cada participante foi desafiado a 
compartilhar uma frase que tivesse despertado alguma curiosidade, ou lhe chamado mais atenção.

Esses encontros que foram explicitados retratam as estratégias que estão sendo propostas a fim de oportunizar uma prática de leitura interativa. Ao solicitar aos participantes que realizem destaques, que elaborem perguntas, que façam desenhos referentes à leitura impinge-se a eles um posicionamento frente ao texto e, com isso se qualifica a prática da leitura. Aliado a isso, foi possivel observar que, fazer com que os participantes sejam os protagonistas da organização faz com que desenvolvam a capacidade de planejamento, a qual será essencial na sua profissão. A fim de qualificar o diálogo frente a essa perspectiva de leitura apresentamos alguns excertos pinçados das escritas de avaliação de alguns participantes ${ }^{4}$.

“(...) as metodologias realizadas foram muito desafiadoras, nos proporcionam discussões pertinentes à nossa formação [...] de forma positiva aponto para a integração do grupo e a abertura de diálogos" $\left(\mathrm{PF}_{1}, 2017\right)$;

"Em relação as metodologias de leitura empregadas, achei muito válido e importante pois foi uma maneira de poder se integrar mais ao grupo. Me senti muito acolhida e estimulada a fazer as leituras e esperar o que estava por vir a cada encontro" (L9, 2017).

"O grupo promoveu em seus encontros várias metodologias e essa dinamicidade instiga nosso aprender e enriquece nossos diálogos. Os TDC que discutimos me fazem ver possibilidades, com relação à docência, além de ser uma leitura prazerosa para

4 Foi solicitado aos participantes que realizassem uma avaliação das metodologias, que destacassem a organização do grupo, que elencassem pontos positivos e/ou negativos. Participaram desse encontro 14 sujeitos e desses, 12 responderam ao questionário, as questões tinham como objetivo qualificar a prática. Para o diálogo apresentado os sujeitos estão indicados por $\mathrm{PF}_{1,2 \ldots}$ - Professor Formador e $\mathrm{L}_{1,2} \ldots$ - licenciando. 
A leitura de textos de divulgação científica...

enriquecer nosso conhecimento pessoal acerca das coisas" $\left(\mathrm{L}_{1}, 2017\right)$.

"As metodologias de leitura e discussão dos textos sempre me fizeram refletir de como a Química está presente em diversas situações da nossa vida. Destaco de forma positiva os conhecimentos cientificos que venho significando com esse grupo". ( $\left.\mathrm{L}_{3}, 2017\right)$.

"O grupo de estudos veio para me auxiliar em leituras de textos de divulgação cientifica, coisa que não costumava realizar antes dos encontros" ( $\left.\mathrm{PF}_{2}, 2017\right)$. (Grifos nossos).

Os excertos pinçados representam o que os participantes mencionaram a respeito das metodologias empregadas, nas suas escritas indicaram tanto os desafios $\left(\mathrm{PF}_{1}\right)$, a multiplicidade $\left(\mathrm{L}_{1}\right)$, bem como, aspectos relacionados com a promoção da integração e da motivação ( $\left.\mathrm{L}_{9}\right)$ para a leitura. O desafio das estratégias de leituras que foi mencionado por $\mathrm{PF}_{1}$ pode ser atribuído em relação ao novo, ao fato de a prática solicitar um posicionamento sobre o texto, seja ao ser desafiado em retratar numa imagem o que tenha significado o texto, ou, em elaborar as perguntas. E, assim, conforme apontam os sujeitos, as estratégias impingem a sua participação, pois se sentem desafiados, tal fato ficou evidenciado na escrita de L9 ao mencionar que "me senti acolhida $e$ estimulada a realizar as leituras".

Esse envolvimento dos participantes como o sentir-se "acolhida" e "estimulada" também retrata o envolvimento com a prática da leitura, Solé (1998) aponta que para uma pessoa se envolver com a leitura precisa se sentir capaz de ler, de compreender o texto tanto na leitura individual como contando com a ajuda do outro. Assim, tanto o texto, a sua forma e a sua linguagem, os diálogos no grupo, como as estratégias para a leitura e o diálogo precisam de alguma forma "atrair" o leitor, assim, esse sentir-se acolhida e o estímulo que $\mathrm{L}_{9}$ apresenta é fundamental para um envolvimento responsivo com a prática da leitura. 
Ainda, com Leontiev (1978) destacamos que os sentidos atribuídos para uma determinada ação podem ser modificados no decorrer da mesma, tornando-a significativa para o sujeito oportunizando o desenvolvimento de novas funções. Assim, o "estimulo" para a leitura que foi mencionado por L9 pode ter sido inicialmente a elaboração da pergunta, ou a escolha de uma figura, se caracterizando como uma ação para desencadear a leitura mas, no processo esse "estimulo" inicial pode ter se modificado, tornando-se uma atividade, atribuindo à prática um modo de aprender, de significar a linguagem da química. Nas palavras do autor (1978, pp. 297 -298), “uma ação é um processo cujo motivo não coincide com o seu objeto (isto é, com aquilo que visa), pois pertence à atividade em que entra a ação considerada". É preciso que a leitura seja percebida como modo de aprender, que tenha finalidades maiores do que o simples fato de realizar a tarefa que foi indicada na estratégia, por exemplo. Leontiev (1978) aponta que esse movimento, essa transição da ação para atividade possibilita novos estádios de desenvolvimentos cognitivos, mas, ressalta que a transição de motivo pode levar muito tempo, pois é necessário que o sujeito tome consciência de novas relações estabelecidas. É importante que os participantes do grupo tornem a leitura uma atividade, que passam a compreender tal prática como modo de aprender.

Nessa direção, destacamos as palavras de $L_{1}$ que ao reportar para a participação no grupo aponta que, "instiga nosso aprender e enriquece nossos diálogos [...] nosso aprendizado". Esse posicionamento indicia a prática da leitura como uma atividade, compreendendo esta como modo de significação. $\mathrm{O}$ enriquecimento apontado por $\mathrm{L}_{1}$ pode ser compreendido como um avanço na apropriação da linguagem, pois para se posicionar frente ao texto é preciso fazer uso coerente das palavras e argumentar sobre elas. Segundo Bakthin, (2010, p. 294), "quando passo a fazer uso da palavra ela vai se tornando minha, pois está compenetrada da minha expressão", e nesse processo, nesse diálogo, a minha palavra, no entendimento do autor, traz junto a palavra dos outros, com diferentes graus de interpretação e de sentidos, e a palavra vai se tornando cada vez mais minha na medida em que faço uso consciente da mesma em diferentes situações. 
A leitura de textos de divulgação científica...

Nesse âmbito reforçamos a importância de possibilitar ao licenciando o entendimento das particularidades da linguagem química pelo uso da mesma, em diferentes situações, como é o caso do grupo de leitura, para, assim, desencadear nele o aprendizado mediante a sua significação. $\mathrm{O}$ licenciando $\mathrm{L}_{3}$ destacou a tomada de consciência sobre a presença da química em seu cotidiano, ao indicar que a participação no grupo, que as leituras instigam a sua reflexão sobre “como a Química está presente em diversas situações da nossa vida". Tal fato pode estar aliado às particularidades da linguagem do TDC, uma vez que o mesmo potencializa esse diálogo dos conhecimentos específicos químicos com os fenômenos do cotidiano, com aspectos históricos e/ou culturais. Tomar consciência sobre isso e, conseguir pensar os fenômenos da vida com um olhar direcionado, específico químico, retrata um início da formação do pensamento químico sobre o mundo (VIGOTSKI, 2000). $\mathrm{E}$ isso, se torna mais premente no contexto atual em que somos constantemente desafiados na tomada de decisão sobre fatos e acontecimentos que requerem a relação do conhecimento químico/científico com o dia a dia.

O mesmo licenciando aponta como positivo os "conhecimentos científicos que venho significando com esse grupo", o que retrata o que diz Vigotski (2000) que o desenvolvimento intelectual do individuo depende de processos intencionais, interativos e mediados pela linguagem. Assim, $\mathrm{L}_{3}$ destaca que fazer uso da linguagem química por meio de um gênero discursivo que favorece a contextualização da mesma e, que o contexto de diálogo estabelecido no grupo está contribuindo para o seu aprendizado, para a significação dos conhecimentos científicos. Esse posicionamento reforça os objetivos de criação do grupo que foi justamente oportunizar a apropriação e a significação da linguagem química, conforme já apontamos anteriormente.

Também, os participantes, assim como foi pinçado da escrita de $\mathrm{L}_{1}$, indicaram que participar do grupo possibilita "ver possibilidades, com relação à docência”, ou seja, ao dar a oportunidade ao licenciando de conhecer outros modos de uso da linguagem química e, aliado a isso, organizar diferentes modos de realizar, de instigar tanto a leitura como o diálogo sobre mesma, se mostrou como um caminho a ser seguido pelo licenciando ao se tornar 
professor. Tais práticas se mostram importantes também ao professor formador, como destacou $\mathrm{PF}_{2}$ "o grupo de estudos veio para me auxiliar em leituras de textos de divulgação científica, coisa que não costumava realizar antes dos encontros". Assim, destacamos que é importante o envolvimento dos professores formadores em diferentes espaços, de buscar ampliar os modos do uso e de compreensão da função da linguagem química frente ao processo de ensinar e aprender. É preciso tomar consciência de que o uso da linguagem química de forma apenas mecânica não mobiliza, não qualifica o pensamento químico sobre o mundo, mas que a mesma é constitutiva na formação do pensamento. O processo de simples memorização assemelha-se com o que Bakhtin (2006) caracteriza como língua morta. O autor (2006) exemplifica esse entendimento com o ato de recitar um poema, que depois de declamado pode muito bem ser esquecido sem, no entanto, modificar, de fato, o sujeito que o declamou. Assim, é importante que o professor esteja atento para os sentidos atribuídos pelos estudantes, pois a simples repetição da palavra indica apenas o processo inicial de apropriação, sendo que a significação não é um caminho linear, mas requer um constante acompanhamento e o uso da palavra em diferentes contextos.

Tendo em vista a prática de leitura que estamos vivenciando reiteramos a importância da ampliação e do acompanhamento dessas práticas em contexto de formação inicial de professores, para que o professor de química se reconheça como leitor e que multiplique, tal prática nas suas salas de aula junto aos seus alunos possibilitando um ensino de química significativo.

\section{Considerações finais}

A prática de leitura vivenciada reitera a visão de que a linguagem química precisa fazer sentido para o sujeito para que ele consiga se apropriar e significar a mesma em diferentes contextos. Esse movimento de apropriação e significação pode ser favorecido por meio da leitura dialogada, uma vez que esta implica numa postura responsiva do leitor. Com o referencial histórico cultural chamamos atenção para o fato de a significação conceitual não ser um processo fácil e automático, mas que requer espaços que possibilitem o uso da linguagem química num processo sistematicamente acompanhado. 
A leitura de textos de divulgação científica...

As estratégias que foram vivenciadas instigaram aos participantes do grupo um posicionamento frente ao texto, seja para a elaboração de perguntas e/ou para a escolha de alguma imagem e/ou excerto do ou sobre o texto. E, aliado a isso, no dia do encontro foi preciso dialogar, justificar as suas escolhas, ouvir e interagir com o outro. Tais aspectos se mostraram como aliados num movimento inicial de constituição de professores leitores que passaram a dialogar mais com e sobre os textos. Com isso, os participantes passaram a fazer uso mais consciente da linguagem química, seja para explicar determinado fenômeno, ou excerto escolhido do TDC. E isso, por sua vez, é um caminho essencial para a significação da linguagem química e para a formação do pensamento químico sobre o mundo.

Em especial, ao olhar para as escritas dos licenciandos e professores formadores foi possivel identificar que o contato/conhecimento de diferentes TDCs além de estimular a leitura por seu modo de apresentar o texto, tornou mais próximo para eles fazer uso desse gênero discursivo, posteriormente, em sala de aula. Aliado a isso estão às múltiplas estratégias vivenciadas e que reforçam a importância de uma prática de leitura dialogada, da importância de um acompanhamento da leitura, da orientação para a realização da mesma. Uma vez que pouco adianta apenas encaminhar textos para os estudantes lerem em casa sem auxiliá-los, sem fazer uma discussão/problematização da sua compreensão, dos sentidos atribuídos ao texto. Reforçamos que a prática da leitura requer que o sujeito se envolva de maneira dialógica com o texto, que ele se posicione frente a ele, para que assim, se constitua um leitor, no caso específico, um professor leitor.

Por fim, esperamos que o ensaio por ora apresentado forneça subsídios que ajudem aos demais professores, pesquisadores da área a ampliar e qualificar o uso da leitura em diferentes espaços formativos, num movimento que qualifique o seu uso e que venha a contribuir para um ensino mais significativo. Acreditamos na necessidade da formação de sujeitos capazes de se posicionar frente a tantas informações e conhecimentos que chegam a cada instante e, reiteramos que o professor tem, neste aspecto, uma função essencial de mediador, de conduzir e auxiliar na formação de sujeitos mais críticos e comprometidos. 


\section{Referências Bibliográficas}

BARBOSA, J. G.; HESS, R. O diário de pesquisa: o estudante universitário e seu processo formativo. Brasília: Liberlivro, 2010, 103p.

BAKHTIN, M. M., Estética da Criação Verbal. Trad. Paulo Bezerra. 5. ed. São Paulo: WMF Martins Fontes, 2010, 476p.

(Volochinov). Marxismo e Filosofia da Linguagem. 12. ed. São Paulo: Hucitec, 2006, 201p.

CUNHA, M. B. da; GIORDAN, M. A Divulgação Científica na sala de aula: Implicações de um Gênero. In: (Orgs). Divulgação Científica na sala de aula: Perspectivas e Possibilidades. Ijuí: Ed. Unijuí, 2015, 67 - 86.

FLÔR, C. C. Na busca de ler para ser em aulas de Quimica. Ijuí: Editora Unijuí, 2015, 208 p.

FERREIRA L. N. de A.; QUEIROZ, S. L. Características discursivas de artigos de divulgação científica relacionados à química. In: Revista Electrónica de Enseñanza de las Ciencias v. 11, n. 1, p. 21-42, 2012.

- Utilização de Textos de Divulgação Científica em Salas de Aula de Química. In: CUNHA, M. B., GIORDAN, M. (Orgs). Divulgação Científica na sala de aula: Perspectivas e Possibilidades. Ijuí: Ed. Unijuí, 2015, $131-159$.

GERALDI, João Wanderley. Ancoragens - Estudos bakthinianos. São Carlos: Pedro \& João Editores, 2010. 176p.

GOUVÊA, G. A Divulgação da Ciência da Técnica e da Cidadania em Sala de Aula In: CUNHA, M. B., GIORDAN, M. (Orgs). Divulgação Científica na sala de aula: Perspectivas e Possibilidades. Ijuí: Ed. Unijuí, 2015, 13 - 42. 
A leitura de textos de divulgação científica...

JUNIOR, J. G. T.; SILVA, R. M. G da. Perfil de Leitores em um Curso de Licenciatura em Química. In: Química Nova, v. 30, n. 5, p. 1365-1368, 2007.

LARROSA, J. Pedagogia Profana: danças, piruetas e mascaradas. Trad. Alfredo Veiga Neto, 5 ed., Belo Horizonte, Autêntica Editora, 2015. 208 p.

LEONTIEV, A. N. O Desenvolvimento do Psiquismo. Trad. M. D. Duarte, Lisboa, Livrso Horizonte, 1978, 354p.

- Uma contribuição à teoria do desenvolvimento da psique infantil. In. VIGOTSKI, L. S. Linguagem, desenvolvimento e aprendizagem, trad. Maria da Penha Villalobos, 10. ed. São Paulo: Ícone, 2006, p.59 - 83.

MARQUES, M. O. Escrever é preciso: o principio da pesquisa. 4. ed., Ijuí, Unijui, 2001, 168 p.

MORAES, R. O significado do aprender: linguagem e pesquisa na reconstrução de conhecimentos. Revista Conjectura, Caxias do Sul, v. 15, n. 1, p. 135-150, jan./abr., 2010.

SACKS, O. Tio Tungstênio: Memórias de uma Infância Química. Companhia das Letras: São Paulo, 2002, p.334.

SCHWARCZ, J. Barbies, Bambolês e Bolas de Bilhar: 67 deliciosos comentários sobre a fascinante Química do dia a dia. Rio de Janeiro: Zahar, 2009.

SOLÉ, I. Estratégias de Leitura. 6 ed. Porto Alegre: Penso, 1998. 194 p.

VIGOTSKI, L. S. A Construção do Pensamento e da Linguagem. Trad. Paulo Bezerra, 1 ed. São Paulo: Martins Fontes, 2000, 296 p. 